Check for updates

Cite this: RSC Adv., 2017, 7, 30792

Received 31st March 2017

Accepted 25th May 2017

DOI: $10.1039 / c 7 r a 03730 a$

rsc.li/rsc-advances

\section{Stimulation of intestinal growth with distal ileal infusion of short-chain fatty acid: a reevaluation in a pig model $\dagger$}

H. Diao, A. R. Jiao, B. Yu, J. He, J. Yu, P. Zheng, Z. Q. Huang, Y. H. Luo, J. Q. Luo, X. B. Mao (D) and D. W. Chen (D)*

In this study, 18 barrows (Duroc $\times$ Landrance $\times$ Yorkshire) with average initial body weight of $30.72( \pm 1.48)$ $\mathrm{kg}$ fitted with a T-cannula in the terminal ileum were randomly allotted to 3 treatments to determine the underlying mechanisms of the regulation role of SCFAs on the intestinal development in a pig model. The treatment groups were: (1) control, (2) antibiotics, Ab, (3) antibiotics + SCFAs (acetic, propionic and butyric acids; $61.84,18.62$, and $12.55 \mathrm{mM}$, respectively). AS. Antibiotics administration decreased total viable bacteria in the porcine feces by 10 folds $(P<0.05)$. Compared with the control group, pigs in the $\mathrm{Ab}$ group had lower SCFAs concentrations in the serum and digesta, as well as decreased SCFAs receptors abundances in the ileum and colon $(P<0.05)$. However, the SCFAs concentrations and SCFAs receptors abundances in the AS group were higher than those of Ab group $(P<0.05)$. SCFAs infusion led to alteration of the intestinal index, morphology and elevation of the intestinal development-related genes abundances and the nutrients digestibility and decreasing of the percentage of apoptotic cells when compared with the Ab group $(P<0.05)$. In addition, SCFAs infusion enhanced TJP1 and MUC-1 abundances and decreased the IL 8 abundance in ileum and colon, which were accompanied by greater numbers of Lactobacillus spp. and Bifidobacterium spp., and less counts of Escherichia coli in these intestinal segments $(P<0.05)$. In conclusion, this study provides the systematic and potent evidences demonstrated that distal ileal infusion of SCFAs could stimulate intestinal growth and improve gut barrier function in a pig model.

\section{Introduction}

Carbohydrates which can't be degraded by the endogenous enzymes derived from pigs themselves are able to be utilized by gut microbiota in the hindgut, and are further transformed into short chain fatty acids (SCFAs) like acetate, propionate and butyrate. ${ }^{1}$ Upon the production of SCFAs, acetate and propionate are firstly absorbed into the bloodstream and then transported to the hepatic cells to regulate lipid and glucose metabolism, while butyrate can be converted to ketone bodies or carbon dioxide for supplying energy to colonic epithelial cells, and the usual proportions of acetate, propionate and butyrate in gut are almost $60: 25: 15 .^{2,3}$ Meanwhile, the simple drop in $\mathrm{pH}$ values of digesta driven by SCFAs has been

Institute of Animal Nutrition, Sichuan Agricultural University, Key Laboratory for Animal Disease-Resistance Nutrition of China Ministry of Education, Xinkang Road 46\#, Ya'an, Sichuan Province 625014, People's Republic of China. E-mail: acatmxb2003@163.com; dwchen@sicau.edu.cn; Fax: +86-835-288-5106; Tel: +86835-288-5106

$\dagger$ Electronic supplementary information (ESI) available. See DOI: 10.1039/c7ra03730a

$\$$ These authors contributed equally to this work. considered to be associated with the maintenance of microbial ecosystem, ${ }^{4}$ and the SCFAs profile in the intestinal content can reflect the metabolic interaction between microorganisms. ${ }^{5}$ Recently, SCFAs have been proved that can activate intestinal gluconeogenesis via complementary mechanisms. ${ }^{6}$

Intestinal mucosa epithelium is one of the most rapid proliferation tissues in the host and its turnover rate usually is 2 to 3 days. $^{7,8}$ Previous studies have shown that SCFAs were involved in intestinal epithelial cell proliferation. An early study on rats revealed that infusing SCFAs mixture into ileum for several days resulted in elevated crypt cell production rate of small intestine, and this effect was dose-dependent of SCFAs but independent of the presence of gut bacteria. ${ }^{9}$ Moreover, SCFAs lost such a stimulatory proliferation effect with the destroying of the vagus nerve or the sympathetic nerve in rats. ${ }^{10}$ Furthermore, colonic infusion of butyrate or a combination of SCFAs increased the concentrations of the mucosal protein, RNA and DNA, as well as the mucosal weight of ileum and colon in rats. ${ }^{11}$ To date, the sole study testing the effects of SCFAs infusion on pigs demonstrated caecal infusion of butyrate stimulated proliferation of epithelial cell in most intestine sites. ${ }^{12}$ However, the inconsistent results were found in a bunch of in vitro studies, demonstrating that SCFAs may inhibit 
intestinal cell proliferation. Sakata first observed this phenomenon in their continuous studies, in which examined the effects of SCFAs on cell proliferation of isolated cecal tissue of rat, and revealed that SCFAs can cause the inhibition of epithelial proliferation. ${ }^{9}$ Likewise, butyrate treatment was found that could decrease cell viability of Caco- 2 cell. ${ }^{13}$ Owing to the big controversy in publications, the effects of SCFAs on intestine cell proliferation still needs to be further investigated.

Gut barrier consists of physical barrier, chemical barrier, biological barrier and immune barrier. Recently, several in vivo studies revealed the critical role of SCFAs in regulating intestinal barrier function. In the physiological concentration, butyrate could enhance intestinal barrier function by increasing the mRNA expression of tight junction-related genes (OCLN and TJP1) and elevating transepithelial electrical resistance (TER) in IPEC-J2 cells. ${ }^{14}$ A recent in vitro study demonstrated that SCFAs treatment elevated epithelial oxygen consumption and resulted in highly stabilization of transcription factor HIF-1, which facilitates the reassembly of tight junction proteins and thus improves epithelial physical barrier function. ${ }^{15}$ Besides, SCFAs have been reported to improve epithelial immune barrier function, as indicated by lower mRNA expressions of proinflammatory cytokines (IL8 and IL1 $\beta$ ) in Caco-2 cells challenged by LPS. ${ }^{16}$ Furthermore, SCFAs can inhibit the growth and colonization of harmful bacteria on the epithelial tissues by decreasing the digesta $\mathrm{pH}$. In an in vitro study, the propionic acid has been shown to reduce the Staphylococcus aureus internalization into bovine mammary epithelial cells. ${ }^{17}$ Additionally, butyrate has been reported to promote mucin secretion through AMP-activated protein kinase (AMPK) signaling pathway, as indicated by higher mRNA expressions of MUC2, MUC3, MUC4 and MUC12 in LS174T human colorectal cells, compared to control group. ${ }^{18}$

However, the effects of SCFAs on intestinal barrier function has been rarely investigated in vivo model. Remarkably, the pig is a better animal model for human nutrition and diseases investigation compared with rodent, since the higher similarity in anatomy and physiology existed between human and pigs. ${ }^{\mathbf{1 9}}$ Taking these into account, the objective of this study was to evaluate the effects of distal ileal infusion of SCFAs on gut development and gut barrier function in a pig model, which could help us to further understand the mechanisms through which SCFAs improves gut health.

\section{Materials and methods}

\section{Animals, management, diets and sample collection}

All animal handling procedures were approved by the Animal Care and Use Committee of Sichuan Agricultural University under permit number DKY-B20131703. A total of 18 barrows (Duroc $\times$ Landrance $\times$ Yorkshire, initial BW $30.72 \pm 1.48 \mathrm{~kg}$ ) equipped with a T-cannula in the distal ileum were randomly allotted to 3 treatments with 6 replicates per treatment and 1 pigs per replicate, and 3 additional pigs fitted with a T-cannula were included in the procedures in case of drop outs. The treatment groups were: (1) control, (2) antibiotics, Ab, (3) antibiotics + SCFAs (acetic, propionic and butyric acids; 61.84,
18.62, and $12.55 \mathrm{mM}$, respectively), AS. Diet was formulated to meet or exceed the nutrient recommendation of NRC (2012) for 25-50 kg pigs (Table S1†).

All the pigs were fasted for 12 hours before installing Tcannula to the distal ileum. The internal diameter, length and wings of the T-cannulas were $1.7,7.4$, and $9.4 \mathrm{~cm}$, respectively. The surgical procedure and post-operative care were conducted as described by Nyachoti et al. (2002) ${ }^{20}$ and Dilger et al. (2004). ${ }^{21}$ All the pigs were conscious within a short time after the surgery and were allowed a $10 \mathrm{~d}$ recovery period. The pigs were individually housed in smooth-walled and plastic-covered expanded metal flooring cages $(1.5 \times 0.8 \times 1.0 \mathrm{~m})$ within a facility equipped with temperature, humidity and light control during the study. The health status of the pigs was monitored at least on a daily basis by manual and visual inspections.

After $10 \mathrm{~d}$ recovering, pigs were given a cocktail of antibiotics treatment (ampicillin, gentamicin, metronidazole, and neomycin (all at $2.4 \mathrm{mg}$ per day) and vancomycin (1.2 mg per day) once daily for 14 consecutive days by oral gavage) except control group to deplete of intestinal microbiota. ${ }^{22,23}$ After antibiotic treatment, a $300 \mathrm{~mL}$ portion of either sodium chloride solution (control and antibiotics groups) or SCFA mixture (acetic, propionic and butyric acids; 61.84, 18.62, and $12.55 \mathrm{mM}$, respectively) was injected into each fistula three times a day at 08:00, 14:00 and 20:00 hours for 14 consecutive days. The $\mathrm{pH}$ of both solutions was adjusted to 6.1 with hydrochloric acid or sodium hydroxide. ${ }^{24}$ The whole trial lasted for 28 days.

Fecal sample of each pig was obtained on d 7, d 14 and d 28, and all the fecal samples were collected into the sterile containers immediately for microbial quantity (plate culture) determinations immediately. During days 24-27, feces of each pig was collected, and $10 \%$ hydrochloric acid was added to fix excreta nitrogen, which was used to measure the apparent total tract digestibility (ATTD) of dry matter (DM), crude ash, crude protein (CP) and ether extract (EE). On d 28, around $3 \mathrm{~h}$ post feeding, pigs were anesthetized by intramuscular injection of $10 \mathrm{mg} \mathrm{kg}{ }^{-1}$ BW of zoletil 50 (Beijing Pet Technology Co., Ltd, Beijing, China), and the blood samples were collected from the portal vein into vacuum tubes and then centrifuged (3000 rpm) for $10 \mathrm{~min}$ to separate serum. The lengths of small intestine and large intestine were measured, and the duodenum, jejunum, ileum and colon were immediately isolated and preserved in $4 \%$ paraformaldehyde solution. This was followed by isolating and preserving the tissues of ileum and colon in phosphate buffer solution (PBS, $4{ }^{\circ} \mathrm{C}$ ), respectively. After that, the digesta of ileum, caecum and colon, and measured each $\mathrm{pH}$ values were collected. Moreover, the weight of small intestine and large intestine were detected and recorded. In addition, the tissues and mucosa of ileum, caecum and colon were immediately collected and stored at $-80{ }^{\circ} \mathrm{C}$. The intestinal index was carried out by the formulas: relative length of intestine $\left(\mathrm{mm} \mathrm{g}^{-1}\right)=$ intestinal length/body weight $\times 100$, relative density of intestine $\left(\mathrm{g} \mathrm{cm}^{-1}\right)=$ intestinal weight/intestinal length, relative weight of intestine $(\%)=$ intestinal weight/body weight $\times 100$. 


\section{Short-chain fatty acid}

Acetic acid, propionic acid, butyric acid and total SCFAs in serum, ileal, caecal and colon digesta samples were separated and then quantified using a gas chromatographic system (VARIAN CP-3800, Varian, Palo Alto, CA, USA) as previously described by Diao et al. $(2014) .^{25}$

\section{Enumeration of total aerobic bacteria and total anaerobic bacteria by plate culture}

The fresh fecal samples were homogenized for 5 min after adding $1: 9$ sterile PBS, and serial dilutions (1:10) were prepared from $10^{-2}$ to $10^{-8}$. Diluted samples were plated on BHI medium (Hopebio, Qingdao, China) following anaerobic and aerobic incubation at $37^{\circ} \mathrm{C}$ for $24 \mathrm{~h}$ to count total aerobic bacteria and total anaerobic bacteria. All bacteria were counted as total $\mathrm{CFU} \mathrm{g}^{-1}$ feces, and expressed as $\log 10 \mathrm{CFU} \mathrm{g}^{-1}$ for statistical analysis.

\section{Apparent total tract digestibility}

The ATTD was determined by endogenous tracer method, using acid-insoluble ash (AIA) as indicator. AIA in both diets and feces were measured by a method described by Chinese National Standard (GB/T 23742). Moreover, all feed and feces were analyzed for DM (method 930.15, AOAC, 1995), EE (method 945.16, AOAC, 1995), crude ash (method 942.05, AOAC, 1995), CP (method 990.03, AOAC, 1995) and GE, and the GE was determined using bomb calorimetry (Parr Instrument 1563, Moline IL).The nutrient digestibility was calculated as the formula (100- $\left.A_{1} B_{2} / A_{2} B_{1} \times 100\right)$, where $A_{1}$ represents the AIA content of the diet; $B_{1}$ represents the nutrient content of the $\operatorname{diet} ; A_{2}$ represents the AIA content of feces; $B_{2}$ represents the nutrient content of feces.

\section{Histology of intestine}

The duodenum, jejunum and ileum were removed from pigs and fixed in $4 \%$ paraformaldehyde solution, and then were dehydrated and embedded in paraffin wax. Intestinal sections of $5 \mu \mathrm{m}$ were cut, installed and stained with hematoxylin and eosin to detect the morphology of the intestinal tissues. Ten well orientated sections (villi height and their adjoined crypts) of each sample were photographed and measured using the light microscope (Olympus, Tokyo, Japan) combined with a digital microscope camera (Olympus Optical Company, Guangzhou, China) and an image-processing software (ImagePro Plus 4.5, Silver Spring, MD, USA) at $100 \times$ magnification. The numbers of goblet cells were determined using alcian blue and periodic acid Schiff (AB-PAS). ${ }^{26}$ All the observations were determined by a single experimenter who was blind to the treatments.

\section{Total protein, cytokines, GLP2 and SIgA concentration}

The mucosa of ileum, cecum and colon were homogenized after dilution with sterile saline solution $(\mathrm{m} / \mathrm{v}=1: 9)$, followed by centrifuging at $2500 \mathrm{rpm} \mathrm{min}{ }^{-1}$ for $15 \mathrm{~min}$, and the aliquots were stored at $-20{ }^{\circ} \mathrm{C}$. The total protein concentration in the ileal and colonic mucosa was determined using commercial kits (Nanjing Jiancheng Institute of Bioengineering, Nanjing, China). The glucagon-like peptide 2 (GLP2), secretory immunoglobulin A (SIgA), interleukin-10 (IL10), interleukin-8 (IL8) and tumor necrosis factor- $\alpha(\mathrm{TNF} \alpha)$ concentrations of the ileal, cecal and colonic mucosa were determined using pig Enzymelinked Immunosorbent Assay Kits from R\&D system (Minneapolis, MN), and quantified using a BioTek Synergy HT microplate reader (BioTek Instruments, Winooski, VT).

\section{Ileal, cecal and colonic DNA concentration}

The genomic DNA was isolated from the frozen ileum, caecum and colon using the TIANamp genomic DNA kit (TIANGEN, Beijing, China) according to the manufacturer's instructions. The concentration of total DNA was analyzed on a spectrophotometer (Beckman Colter DU 800, Beckman Coulter Inc, Brea, USA).

\section{Enumeration of Escherichia coli, Lactobacillus spp., Bifidobacterium spp., Bacillus spp., and total bacteria by PCR}

Bacterial DNA was isolated from the digesta of ileum, cecum and colon using a stool DNA isolation kit (Omega Bio-Tek, Doraville, CA) following the manufacturer's protocol. Primers and probes (Table $\mathrm{S} 3 \dagger$ ) for Lactobacillus spp., Bifidobacterium spp., Escherichia coli, Bacillus spp. and total bacteria were acquired from the published papers, ${ }^{27,28}$ and commercially synthesized from Sangon Biotech (Shanghai, China). The reaction system and PCR conditions used in present study were referring to Qi et al. (2011). ${ }^{27}$ The Lactobacillus spp., Bifidobacterium spp., Escherichia coli, Bacillus spp. and total bacteria can be detected by the CFX96 Real-Time PCR Detection System (Bio-Rad, CA, USA), and the copies per sample were calculated with Ct-values and standard curve as previously described by Han et al. (2012). ${ }^{29}$

\section{Apoptosis and cell cycle of ileal and colonic epithelial cell by flow cytometry}

On $28 \mathrm{~d}$, the epithelial cells of ileum and colon were isolated to determine the percentage of apoptotic cells and cell cycle by flow cytometry. Briefly, the excised mucosal layer of ileum and colon were immediately isolated, ground and filtered to form a cell suspension. Then, the cells were washed and suspended in phosphate buffer solution at a concentration of $1 \times 10^{6}$ cells per $\mathrm{mL}$. After that, $5 \mu \mathrm{L}$ Annexin V-fluorescein isothiocyanate (VFITC) and $5 \mu \mathrm{L}$ propidium iodide (PI) were added into $100 \mu \mathrm{L}$ cell suspension, and incubated at room temperature for $15 \mathrm{~min}$ in the dark. This was followed by adding $400 \mu \mathrm{L} 1 \times$ binding buffer, and then mixed thoroughly. The apoptotic cells were carried out using Cell Quest software by flow cytometry (BD FACSCalibur) within $1 \mathrm{~h}$.

Likewise, $1 \mathrm{~mL}$ 0.25\% Triton X-100 was added into $100 \mu \mathrm{L}$ cell suspension, then mixed and incubated at $4{ }^{\circ} \mathrm{C}$ for $30 \mathrm{~min}$, centrifuged at $1000 \mathrm{rpm}$ for $5 \mathrm{~min}$. After that, the supernatant was discarded, and $5 \mu \mathrm{L}$ PI was added. Then incubated at $4{ }^{\circ} \mathrm{C}$ for $30 \mathrm{~min}$. This was followed by adding $500 \mu \mathrm{L}$ pre-cooling PBS, and then mixed thoroughly. The cell cycle was measured using 
Modifit software by flow cytometry (BD FACSCalibur) within $1 \mathrm{~h}$. The cell proliferation index (PI) was carried out by the formula: $\mathrm{PI}=\left(\mathrm{S}+\mathrm{G}_{2} \mathrm{M}\right) /\left(\mathrm{G}_{0} \mathrm{G}_{1}+\mathrm{S}+\mathrm{G}_{2} \mathrm{M}\right) \times 100 \%$.

Total RNA extraction, reverse transcription reaction and realtime quantitative PCR

Total RNA was isolated from the frozen mucosa of ileum and colon using the TRIzol reagent (Biotechnology Company, Dalian, China) according to the manufacturer's instructions. The cDNA of each sample was obtained by reverse transcription with a PrimeScript RT reagent kit (Biotechnology Company, Dalian, China). The genes related to cell apoptosis and cycle (BCL2, BCL-2, apoptosis regulator; BAX, BCL-2 associated X, apoptosis regulator; CASP3, caspase-3; CCND1, cyclin D1; CDKN1A, cyclin dependent kinase inhibitor 1A), intestinal development (EGF, epidermal growth factor; GCG, also known as GLP2, glucagon; GLP2R, glucagon-like peptide 2 receptor; IGF1, insulin like growth factor-1; IGF1R, insulin like growth factor-1 receptor), digestion and absorption (SLC5A1, also known as SGLT1, solute carrier family 5 member 1; SLC2A2, also known as GLUT2, solute carrier family 2 member 2; SLC30A1, also known as ZNT1, solute carrier family 30 member 1; SLC11A2, also known as DMT1, solute carrier family 11 member 2; SLC7A1, solute carrier family 7), intestinal barrier (MUC1, mucin 1, cell surface associated; MUC2, mucin 2, oligomeric mucus/gel-forming; OCLN, occludin; TJP1, also known as ZO1, tight junction protein 1; CLDN1, claudin-1; IL10, interleukin-10; IL1 $\beta$, interleukin-1 $\beta$; IL8, interleukin-8; TNF $\alpha$, tumor necrosis factor) and SCFAs receptors (FFAR3, also known as FFAR3, free fatty acid receptor 2; FFAR2, also known as GPR43, free fatty acid receptor 2) can be detected by the QuantStudio $^{\mathrm{TM}}$ Real-Time PCR System (Thermo Fisher Scientific, Shanghai, China) as described by Diao et al. (2016). ${ }^{30}$ The primers were synthesized commercially by Invitrogen (Shanghai, China), which were listed in Table S2.†

\section{Statistical analysis}

Data were analyzed by ANONA using the statistic software SAS 9.1 (SAS Inst. Inc., NC) where each pig was the statistical unit. All differences were considered significant at $P<0.05$, whereas $P$ values between 0.05 and 0.10 were considered a trend. All the results were expressed as mean and SEM.

\section{Results}

\section{Antibacterial effect of antibiotics (enumeration of cultivable fecal bacteria)}

As shown in Table 1, pigs treated with high dose of antibiotics with/without SCFAs infusion exhibited lower numbers of aerobic bacteria, anaerobic bacteria and total bacteria in feces on d 7, d 14 and d 28 compared to those in the control group $(P<$ 0.05). Moreover, the total fecal bacteria counts of antibiotictreated pigs were more than 10 folds less than the count in untreated pigs on $\mathrm{d} 7$ and d 14, whereas the difference on d 28 is not that high, less than 10 folds.
Table 1 Effect of combination of antibiotics on the numbers of fecal microbiota in growing pigs $\left(\mathrm{CFU} \times 10^{8}\right.$ per g) ${ }^{a}$

\begin{tabular}{|c|c|c|c|c|c|}
\hline Items & Control & $\mathrm{Ab}$ & $\begin{array}{l}\mathrm{Ab}+ \\
\text { SCFAs (AS) }\end{array}$ & SEM & $P$ values \\
\hline \multicolumn{6}{|l|}{$7 \mathrm{~d}$} \\
\hline Aerobic bacteria & $9.333^{b}$ & $0.364^{c}$ & $0.488^{c}$ & 0.697 & $<0.001$ \\
\hline Anaerobic bacteria & $21.194^{b}$ & $2.161^{c}$ & $1.911^{c}$ & 0.839 & $<0.001$ \\
\hline Total bacteria & $30.528^{b}$ & $2.525^{c}$ & $2.201^{c}$ & 1.151 & $<0.001$ \\
\hline \multicolumn{6}{|l|}{$14 \mathrm{~d}$} \\
\hline Aerobic bacteria & $7.956^{b}$ & $0.230^{c}$ & $0.317^{c}$ & 0.812 & $<0.001$ \\
\hline Anaerobic bacteria & $16.944^{b}$ & $1.958^{c}$ & $2.283^{c}$ & 1.310 & $<0.001$ \\
\hline Total bacteria & $24.900^{b}$ & $2.188^{c}$ & $2.601^{c}$ & 1.987 & $<0.001$ \\
\hline \multicolumn{6}{|l|}{$28 \mathrm{~d}$} \\
\hline Aerobic bacteria & $6.445^{b}$ & $0.703^{c}$ & $0.650^{c}$ & 1.139 & 0.007 \\
\hline Anaerobic bacteria & $11.917^{b}$ & $3.986^{c}$ & $3.764^{c}$ & 1.332 & 0.002 \\
\hline Total bacteria & $18.361^{b}$ & $4.689^{c}$ & $4.764^{c}$ & 2.057 & 0.001 \\
\hline
\end{tabular}

${ }^{a}$ Ab, pigs treated with antibiotics; Ab + SCFAs (AS), pigs treated with antibiotics and SCFAs (acetic, propionic and butyric acids; 61.84, 18.62 , and $12.55 \mathrm{mM}$ respectively). ${ }^{b}$ Within a row, means a common superscript differ $(P<0.05) .{ }^{c}$ Without a row, means a common superscript differ $(P<0.05)$.

\section{Short-chain fatty acids and their receptors}

When compared to the control group, pigs treated with high dose of antibiotics without SCFAs infusion had lower contents of propionic acid and total SCFAs in the serum and ileum, and lower content of butyric acid in the ileum and colon $(P<0.05$, Table 2). When compared to the Ab group, high dose antibiotics treatment combined with SCFAs infusion significantly increased the concentrations of acetic acid, propionic acid, butyric acid and total SCFAs in the serum, ileum and colon, and increased the concentrations of acetic acid, butyric acid and total SCFAs in the cecum $(P<0.05)$. Meanwhile, compared with control group, Ab group had lower FFAR3 mRNA abundance in the colon and lower FFAR2 mRNA abundance in the ileum and colon $(P<0.05$, Fig. 4). On the contrary, the relative mRNA expressions of FFAR3 in the colon and FFAR2 in both ileum and colon were higher in AS group than those in Ab group $(P<0.05)$.

\section{Intestinal index and $\mathbf{p H}$ values}

The relative lengths of small intestine and total intestine, and the relative weight of large intestine in pigs treated with high dose of antibiotics without SCFAs infusion were lower than those in the control group $(P<0.05$, Table 3$)$. However, pigs treated with high dose of antibiotics with SCFAs infusion had higher relative length of small intestine and total intestine, and the relative weight of large intestine and total intestine compared with the Ab group $(P<0.05)$.

High dose of antibiotics supplementation significantly increased the $\mathrm{pH}$ values of digesta in the ileum and cecum compared with the control group $(P<0.05)$. By contrast, compared with the Ab group, high dose antibiotics treatment combined with SCFAs infusion significantly decreased the $\mathrm{pH}$ values of digesta in the colon $(P<0.05)$. 
Table 2 Effect of SCFAs on SCFA concentration of serum, ileum, cecum and colon in growing pigs $(\mu \mathrm{mol} \mathrm{g})^{-1}$

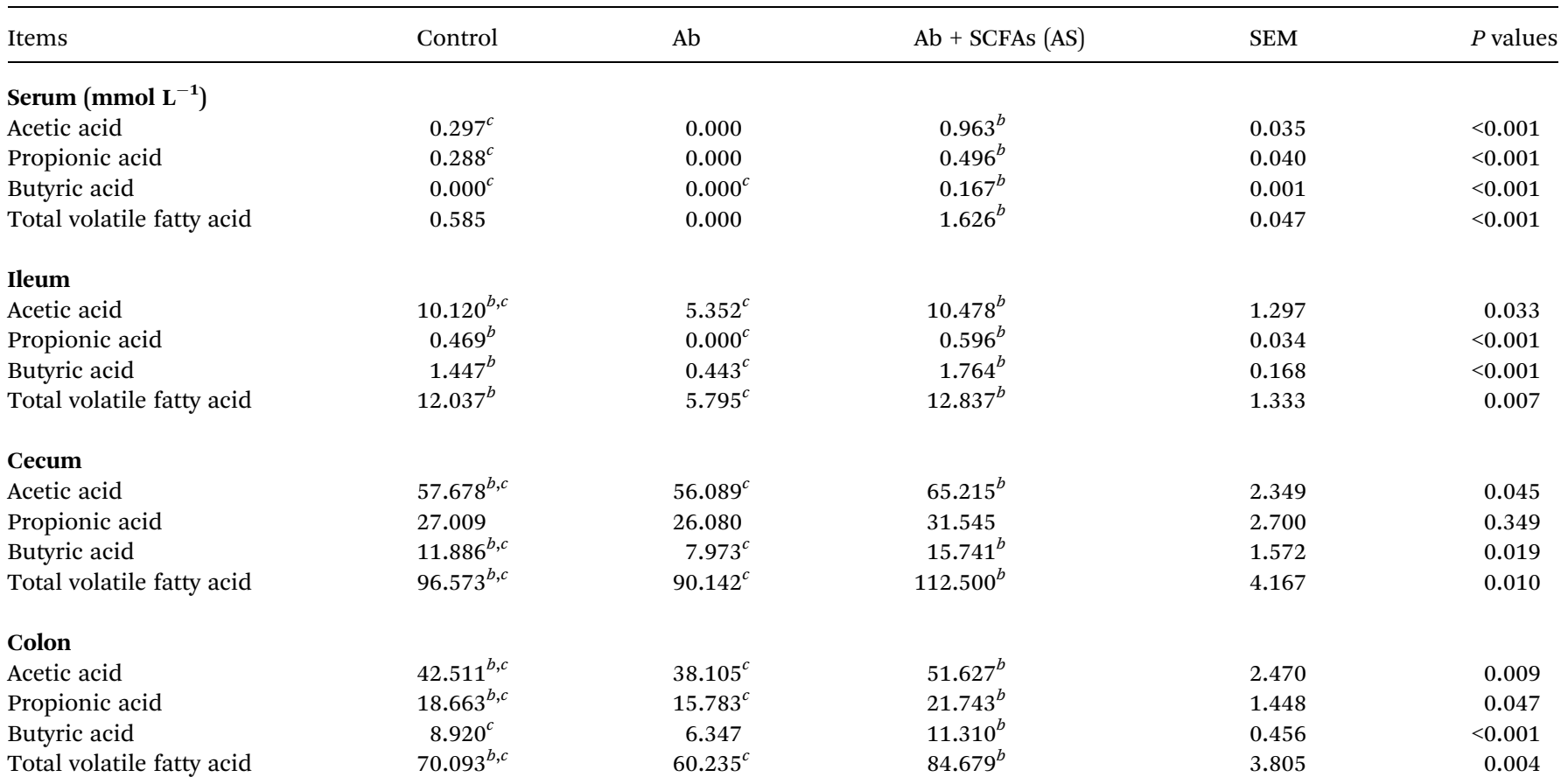

${ }^{a} \mathrm{Ab}$, pigs treated with antibiotics; $\mathrm{Ab}+\mathrm{SCFAs}$ (AS), pigs treated with antibiotics and SCFAs (acetic, propionic and butyric acids; $61.84,18.62$, and $12.55 \mathrm{mM}$ respectively). ${ }^{b}$ Within a row, means a common superscript differ $(P<0.05) .{ }^{c}$ Without a row, means a common superscript differ $(P<0.05)$.

Table 3 Effect of SCFA on intestinal index and $\mathrm{pH}$ values in growing pigs ${ }^{a}$

\begin{tabular}{|c|c|c|c|c|c|}
\hline \multicolumn{6}{|l|}{ Intestinal index } \\
\hline Relative length of SI $\left(\mathrm{cm} \mathrm{g}^{-1}\right)$ & $2.751^{b}$ & $2.521^{c}$ & $2.790^{b}$ & 0.030 & $<0.001$ \\
\hline Relative length of I $\left(\mathrm{cm} \mathrm{g}^{-1}\right)$ & $3.487^{b}$ & $3.218^{c}$ & $3.547^{b}$ & 0.035 & $<0.001$ \\
\hline Relative weight of SI & 2.821 & 2.685 & 2.873 & 0.077 & 0.255 \\
\hline Relative weight of LI & $1.829^{b}$ & $1.628^{c}$ & $1.880^{b}$ & 0.034 & $<0.001$ \\
\hline Relative density of LI $\left(\mathrm{g} \mathrm{cm}^{-1}\right)$ & 2.504 & 2.359 & 2.488 & 0.115 & 0.637 \\
\hline Relative density of $\mathrm{I}\left(\mathrm{g} \mathrm{cm}^{-1}\right)$ & 1.333 & 1.341 & 1.341 & 0.023 & 0.962 \\
\hline \multicolumn{6}{|l|}{ pH values } \\
\hline Jejunum & 6.398 & 6.711 & 6.383 & 0.105 & 0.090 \\
\hline Ileum & $6.187^{c}$ & $6.841^{b}$ & $6.412^{b, c}$ & 0.092 & 0.011 \\
\hline
\end{tabular}

${ }^{a} \mathrm{Ab}$, pigs treated with antibiotics; Ab + SCFAs (AS), pigs treated with antibiotics and SCFAs (acetic, propionic and butyric acids; 61.84, 18.62, and $12.55 \mathrm{mM}$ respectively); SI, small intestine; LI, large intestine; I, intestine. ${ }^{b}$ Within a row, means a common superscript differ $(P<0.05) .{ }^{c}$ Without a row, means a common superscript differ $(P<0.05)$.

\section{Intestinal morphology}

Compared with the control group, high dose of antibiotics supplementation significantly increased the crypt depth and decreased the villus height: crypt depth of duodenum $(P<0.05$, Table 4 and Fig. 1). However, the villus height of duodenum and jejunum and villus height: crypt depth of duodenum, jejunum and ileum in AS group were higher than those in the Ab group $(P<0.05)$. Additionally, compared with the Ab group, AS group had greater numbers of goblet cells in the ileum and colon $(P<0.05)$. 
Table 4 Effect of SCFA on intestinal morphology and numbers of goblet cells in growing pigs ${ }^{a}$

\begin{tabular}{|c|c|c|c|c|c|}
\hline Items & Control & $\mathrm{Ab}$ & Ab + SCFAs (AS) & SEM & $P$ values \\
\hline \multicolumn{6}{|l|}{ Duodenum } \\
\hline Villus height, $\mu \mathrm{m}$ & $610.05^{b, c}$ & $579.20^{c}$ & $667.55^{b}$ & 20.375 & 0.034 \\
\hline Villus height: crypt depth & $2.97^{a}$ & $2.52^{c}$ & $3.17^{b}$ & 0.099 & 0.003 \\
\hline \multicolumn{6}{|l|}{ Jejunum } \\
\hline Villus height: crypt depth & $3.12^{b, c}$ & $2.91^{c}$ & $3.37^{b}$ & 0.095 & 0.020 \\
\hline \multicolumn{6}{|l|}{ Ileum } \\
\hline Villus height, $\mu \mathrm{m}$ & 481.08 & 459.13 & 485.23 & 13.259 & 0.364 \\
\hline Crypt depth, $\mu \mathrm{m}$ & 224.52 & 234.23 & 204.03 & 8.721 & 0.088 \\
\hline Villus height: crypt depth & $2.16^{b, c}$ & $1.97^{c}$ & $2.48^{b}$ & 0.101 & 0.043 \\
\hline
\end{tabular}

${ }^{a} \mathrm{Ab}$, pigs treated with antibiotics; Ab + SCFAs (AS), pigs treated with antibiotics and SCFAs (acetic, propionic and butyric acids; 61.84, 18.62, and $12.55 \mathrm{mM}$ respectively). ${ }^{b}$ Within a row, means a common superscript differ $(P<0.05) .{ }^{c}$ Without a row, means a common superscript differ $(P<0.05)$.

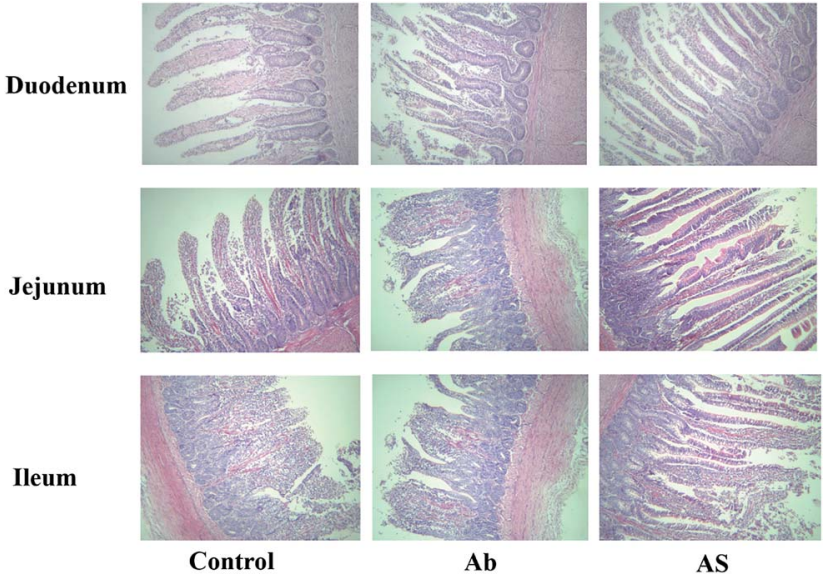

Fig. 1 Histological evaluation of small intestine tissues (H\&E; $\times 100)$ in growing pigs after exposure to antibiotics and SCFAs. Ab, pigs treated with antibiotics; $A b+$ SCFAs (AS), pigs treated with antibiotics and SCFAs (acetic, propionic and butyric acids; $61.84,18.62$, and $12.55 \mathrm{mM}$ respectively). Scale bar is $100 \mathrm{~mm}$.

\section{Apparent total tract digestibility and digestion and absorption-related genes in small intestine}

Compared with the Ab group, pigs treated with high dose of antibiotics with SCFAs infusion had higher ATTD of EE, DM, $\mathrm{CP}$, gross energy and crude ash $(P<0.05$, Table 5). Besides, as shown in Fig. 4, pigs treated with high dose of antibiotics with or without SCFAs infusion had lower SLC2A2 and SLC11A2 mRNA expression levels in ileum than those in the control group $(P<0.05)$. Nonetheless, pigs in the Ab group had lower relative mRNA expressions of SLC5A1, SLC7A1 and SLC30A1 in ileum than those in the control group, whereas SCFAs infusion significantly increased the relative mRNA expressions of
SLC5A1, SLC2A2, SLC7A1, SLC30A1 and SLC11A2 compared with the $\mathrm{Ab}$ group in growing pigs $(P<0.05)$.

\section{Intestinal cell apoptosis and cell cycle}

Compared with the control group, high dose of antibiotics supplementation significantly increased the percentages of early apoptotic cells, late apoptotic cells and total apoptotic cells in the colon $(P<0.05$, Table 6 and Fig. 2). However, the proportions of early apoptotic cells of the ileum, late apoptotic cells and total apoptotic cells of the ileum and colon in AS group were lower than those in the Ab group $(P<0.05)$. Pigs in the Ab group had higher ratio of $\mathrm{G}_{0} \mathrm{G}_{1}$ phase cells but lower proportions of proliferation index of the ileum than those in the control group $(P<0.05$, Table 6 and Fig. 3$)$. Compared with the $\mathrm{Ab}$ group, SCFAs infusion significantly decreased the proportions of $\mathrm{G}_{0} \mathrm{G}_{1}$ phase cells in the ileum and colon, and increased

Table 5 Effect of SCFA on apparent total tract digestibility in growing pigs $^{a}$

\begin{tabular}{llllll}
\hline Items & Control & $\mathrm{Ab}$ & $\begin{array}{l}\text { Ab }+ \\
\text { SCFAs (AS) }\end{array}$ & SEM & $P$ values \\
\hline Ether extract & $67.714^{b, c}$ & $66.558^{c}$ & $74.855^{b}$ & 1.928 & 0.025 \\
Dry matter & $84.961^{b, c}$ & $84.301^{c}$ & $87.799^{b}$ & 0.813 & 0.028 \\
Crude ash & $59.762^{b, c}$ & $57.296^{c}$ & $65.743^{b}$ & 2.089 & 0.044 \\
Crude protein & $79.299^{c}$ & $79.812^{c}$ & $84.672^{b}$ & 1.206 & 0.019 \\
Gross energy & $84.333^{b, c}$ & $84.090^{c}$ & $87.731^{b}$ & 0.877 & 0.026
\end{tabular}

${ }^{a} \mathrm{Ab}$, pigs treated with antibiotics; Ab + SCFAs (AS), pigs treated with antibiotics and SCFAs (acetic, propionic and butyric acids; 61.84, 18.62 , and $12.55 \mathrm{mM}$ respectively). ${ }^{b}$ Within a row, means a common superscript differ $(P<0.05) .{ }^{c}$ Without a row, means a common superscript differ $(P<0.05)$. 
Table 6 Effect of SCFA on apoptosis and cell cycle of ileum and colon in growing pigs $^{a}$

\begin{tabular}{lllll} 
Control & $\mathrm{Ab}$ & $\mathrm{Ab}+$ & & \\
SCFAs (AS) & SEM & $P$ values \\
\hline
\end{tabular}

\section{Ileum}

Early apoptotic cells Late apoptotic cells Total apoptotic cells $\mathrm{G}_{0} \mathrm{G}_{1}$ phase cells $S$ phase cells $\mathrm{G}_{2} \mathrm{M}$ phase cells PI

$\begin{array}{ccc}12.614 & 14.552 & 6.762 \\ 24.940^{b, c} & 37.080^{b} & 12.484^{c} \\ 37.554^{b} & 51.632^{b} & 19.246^{c} \\ 70.640^{c} & 83.420^{b} & 58.380 \\ 22.780^{c} & 13.548^{c} & 24.920^{b} \\ 6.578^{c} & 3.020^{c} & 16.720^{b} \\ 29.358^{c} & 16.570 & 41.632^{b}\end{array}$

\section{$\begin{array}{ll}2.509 & 0.134\end{array}$}

$4.271 \quad 0.011$

$3.669<0.001$

$2.031<0.001$

$1.449 \quad 0.001$

$1.313<0.001$

$2.028<0.001$

\section{Colon}

Early apoptotic cells Late apoptotic cells Total apoptotic cells $\mathrm{G}_{0} \mathrm{G}_{1}$ phase cells $\mathrm{S}$ phase cells $\mathrm{G}_{2} \mathrm{M}$ phase cells PI

$\begin{array}{crr}2.589^{c} & 9.970^{b} & 1.296^{c} \\ 6.320^{c} & 14.348^{b} & 1.014^{c} \\ 8.909^{c} & 24.318^{b} & 2.309^{c} \\ 58.680^{b} & 63.860^{b} & 44.200^{c} \\ 21.720^{c} & 18.900^{c} & 32.325^{b} \\ 15.360^{b, c} & 12.750^{c} & 21.100^{b} \\ 38.688^{c} & 32.958^{c} & 54.657^{b}\end{array}$

1.586

$\begin{array}{ll}1.937 & 0.004\end{array}$

$1.840<0.001$

$\begin{array}{ll}2.178 & 0.001\end{array}$

$\begin{array}{ll}2.369 & 0.009\end{array}$

$\begin{array}{ll}1.759 & 0.027\end{array}$

$2.888 \quad 0.002$
${ }^{a}$ Ab, pigs treated with antibiotics; Ab + SCFAs (AS), pigs treated with antibiotics and SCFAs (acetic, propionic and butyric acids; 61.84, 18.62 , and $12.55 \mathrm{mM}$ respectively); PI: proliferation index, PI $=(\mathrm{S}+$ $\left.\mathrm{G}_{2} \mathrm{M}\right) \times 100 \% .{ }^{b}$ Within a row, means a common superscript differ $(P$ $<0.05) .{ }^{c}$ Without a row, means a common superscript differ $(P<0.05)$.
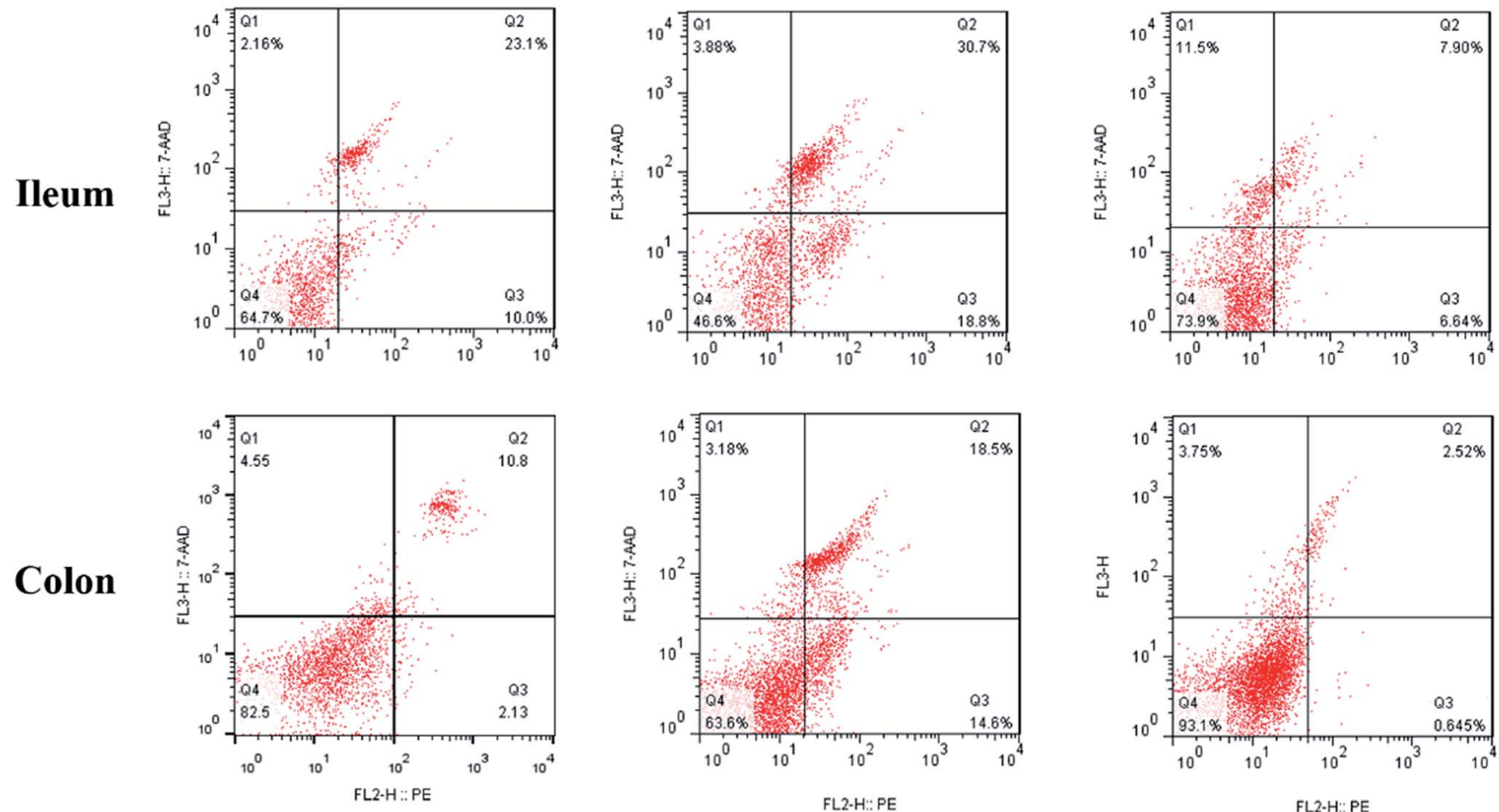

Control the proportions of $\mathrm{S}$ phase cells, $\mathrm{G}_{2} \mathrm{M}$ phase cells and proliferation index in the ileum and colon $(P<0.05)$.

Meanwhile, as shown in Fig. 4, high dose of antibiotics supplementation significantly increased the relative mRNA expressions of BAX and CASP3 in the ileum, and CDKN1A in the ileum and colon compared with the control group $(P<0.05)$. Compared with the $\mathrm{Ab}$ group, the relative mRNA expressions of ileal and colonic BAX, CASP3 and CDKN1A in the AS group were significantly decreased, whereas the relative mRNA expressions of BCL2 and CCND1 in the AS group were significantly increased $(P<0.05)$.

\section{Intestinal DNA and protein concentrations, and relative mRNA expression of intestinal development-related genes}

As shown in Table 7, high dose of antibiotics supplementation significantly decreased the DNA concentration in the ileum compared with the control group $(P<0.05)$. Pigs in the AS group had higher concentrations of DNA in the ileum $(P<0.05)$, cecum $(P=0.071)$ and colon $(P<0.05)$, and had higher contents of protein in the ileum, cecum and colon $(P<0.05)$ than those in the Ab group.

Pigs treated with high dose of antibiotics had lower GLP2R $(P$ $=0.068)$ and IGF1R $(P<0.05)$ mRNA abundances in the ileum, lower EGF $(P<0.05)$, IGF1R $(P<0.05)$ and GLP2R $(P<0.05)$ mRNA abundances in the colon compared with the control group (Fig. 4). Moreover, pigs in the AS group had higher EGF

\footnotetext{
Fig. 2 Evaluation of ileal and colonic cell apoptosis by flow cytometry in growing pigs after exposure to antibiotics and SCFAs. Ab, pigs treated with antibiotics; Ab + SCFAs (AS), pigs treated with antibiotics and SCFAs (acetic, propionic and butyric acids; 61.84, 18.62, and 12.55 mM respectively). Q1, the percentage of necrotic cells; Q2; the percentage of late apoptotic cells; Q3, the percentage of early apoptotic cells; Q4, the percentage of normal cells.
} 

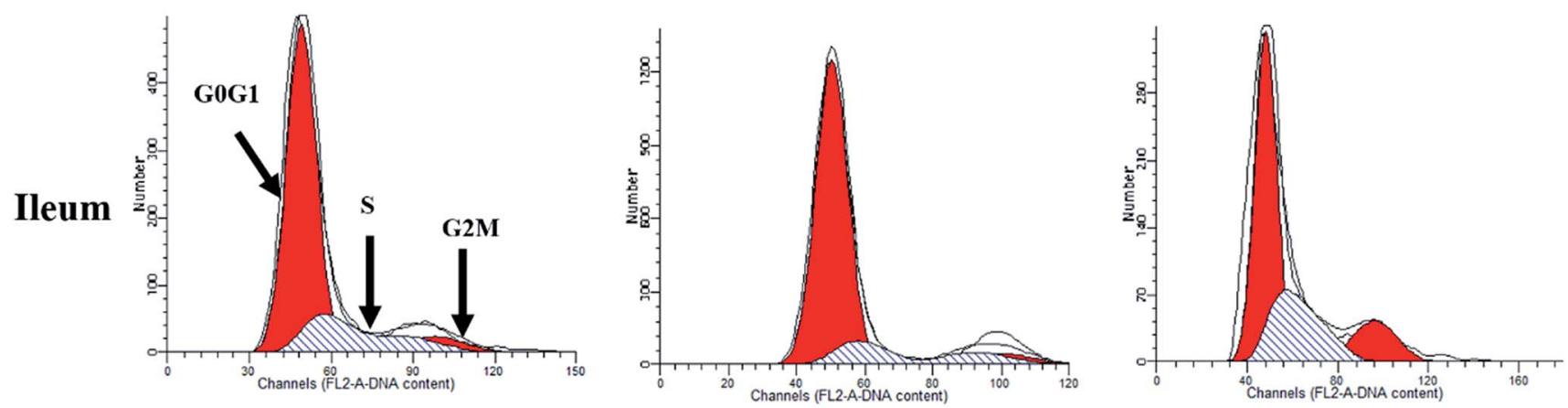

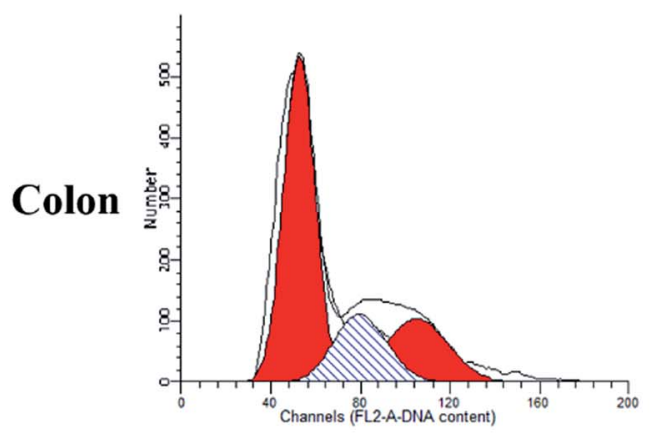

Control

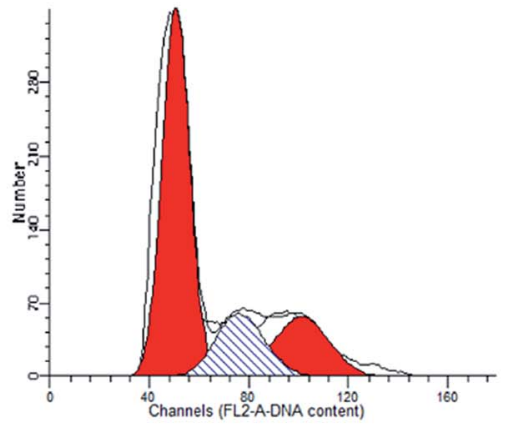

Ab

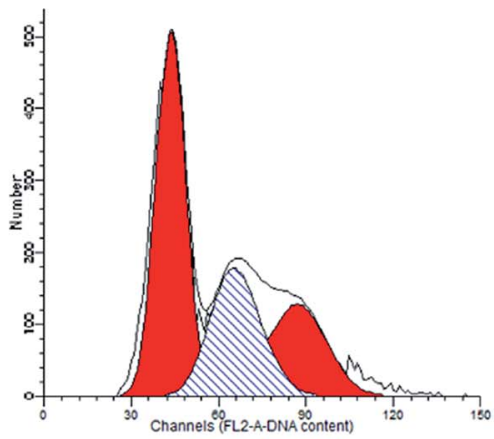

AS

Fig. 3 Evaluation of ileal and colonic cell cycle by flow cytometry in growing pigs after exposure to antibiotics and SCFAs. Ab, pigs treated with antibiotics; Ab + SCFAs (AS), pigs treated with antibiotics and SCFAs (acetic, propionic and butyric acids; $61.84,18.62$, and 12.55 mM respectively).

mRNA abundance in the ileum, GLP2R mRNA abundance in the colon, as well as GCG, IGF1 and IGF1R mRNA abundances in the ileum and colon than those in the Ab group $(P<0.05)$. In addition, Ab group had lower GLP2 concentration in the ileum $(P<0.05)$, cecum $(P=0.055)$ and colon $(P<0.05)$ compared with the control group, whereas pigs in AS group had a higher GLP2 concentration in the ileum $(P<0.05)$, cecum $(P=0.055)$ and colon $(P<0.05)$ than that in the Ab group (Table 8$)$.

\section{Intestinal barrier}

As shown in Fig. 5, Ab group had lower CLDN1 mRNA abundance in the ileum, TJP1 and CLDN1 mRNA abundances in the ileum and colon compares with the control group $(P<0.05)$. Pigs in the AS group had higher TJP1 mRNA abundance in the ileum and colon, OCLN and CLDN1 mRNA abundances in the ileum than those in the Ab group $(P<0.05)$. Besides, high dose of antibiotics administration significantly decreased the relative mRNA expressions of MUC2 in the ileum compared with the control group, and SCFAs infusion significantly increased the relative mRNA expressions of MUC1 and MUC2 in the ileum and colon compared with the Ab group $(P<0.05)$. Moreover, $\mathrm{Ab}$ group had lower relative mRNA expressions of IL10, IL1 $\beta$ and TNF $\alpha$ in the colon and lower IL8 mRNA expression level in both of the ileum and colon compared with the control group, whereas pigs in the AS group had a higher relative IL10 mRNA abundance, and a lower IL8 mRNA abundance in the ileum and colon than those in the Ab group $(P<0.05)$. Pigs treated with high dose of antibiotics with/without SCFAs infusion significantly decreased the IL1 $\beta$ and TNF $\alpha$ mRNA abundances in the colon, IL8 mRNA abundance in the ileum and colon compared with the control group $(P<0.05)$. In addition, Ab group had lower contents of IL10 in the ileum and cecum, lower contents of IL8 in the ileum, and lower concentration of TNF $\alpha$ in the ileum and colon, as well as lower contents of SIgA in the colon compared with the control group, and AS group had higher contents of IL10 in the ileum, higher contents of SIgA in the colon and lower contents of IL8 and TNF $\alpha$ in the ileum and cecum compared with the Ab group $(P<0.05$, Table 8$)$. Finally, high dose of antibiotics supplementation significantly decreased the numbers of Bacillus spp., Escherichia coli, Lactobacillus spp. and Bifidobacterium spp. in the ileum, cecum and colon compared with the control group $(P<0.05$, Table 9). SCFAs infusion significantly increased the counts of Bacillus spp., Lactobacillus spp. and Bifidobacterium spp., and decreased the counts of Escherichia coli in the ileum, cecum and colon compared with the Ab group $(P<0.05)$.

\section{Discussion}

In order to suppress the interference from endogenous SCFAs produced by gut microbiota and investigate the effects of exogenous infused SCFAs, we attempted to deplete the intestinal microbiota of selected pigs in the present trial by providing gentamicin, ampicillin, metronidazole, vancomycin and neomycin, which were commonly used to deplete gut microbiota on mice. ${ }^{22,23}$ Unfortunately, combination of these antibiotics decreased total viable bacteria in feces only for more than 10 folds on $\mathrm{d} 7$ and d 14, and less than 10 folds on d 28 in our 

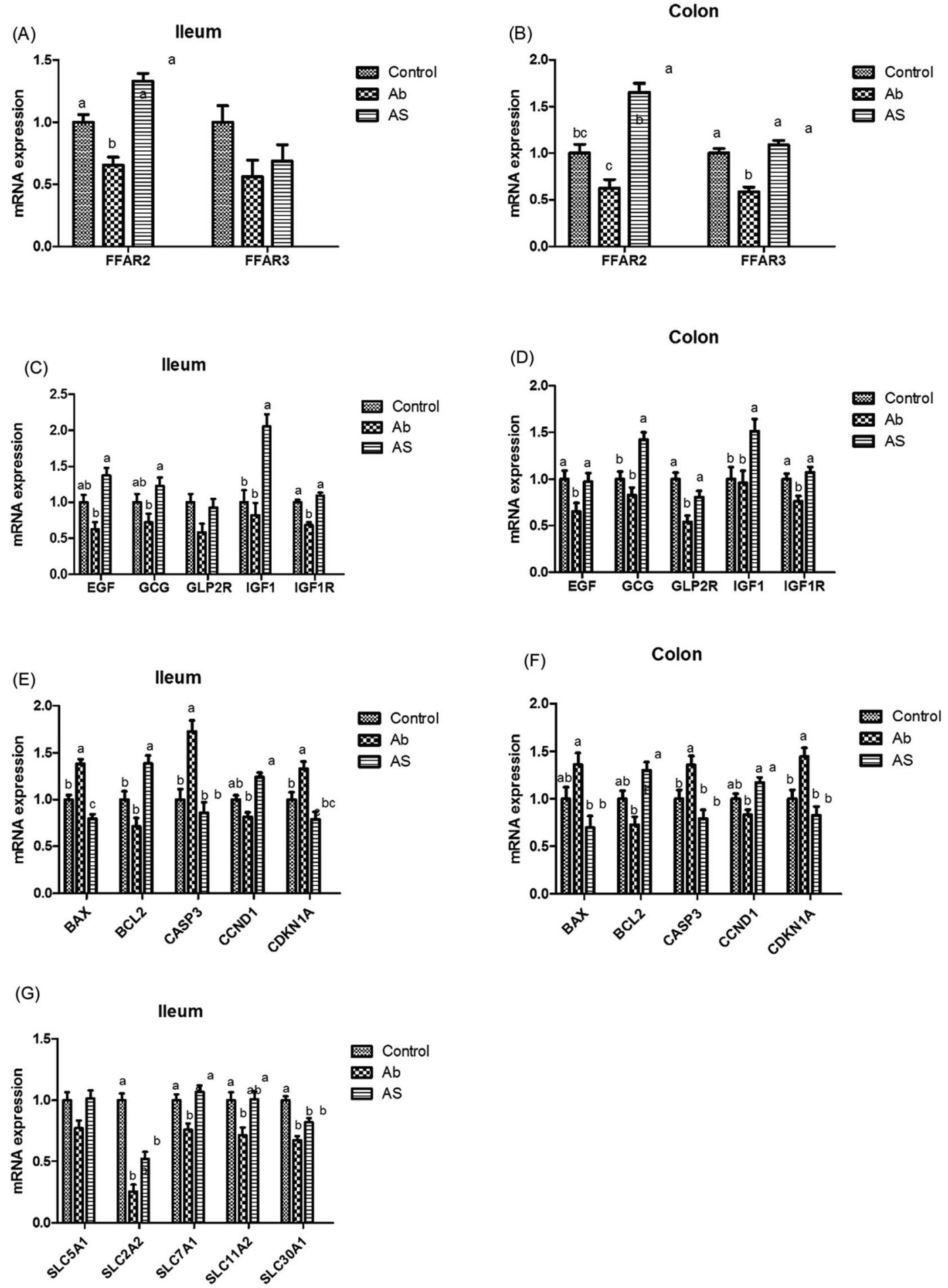

Fig. 4 The relative mRNA expressions of SCFA receptors, intestinal development-related genes, cell apoptosis and cycle-related genes, digestion and absorption-related genes. (A and B) Relative amounts of FFAR3 and FFAR2 mRNAs in ileum and colon of growing pigs. (C and D) Relative amounts of EGF, GCG, GLP2R, IGF1, IGF1R mRNAs in ileum and colon of growing pigs. (E and F) Relative amounts of BAX, BCL2, CASP3, CCND1 and CDKN1A mRNAs in ileum and colon of growing pigs. (G) Relative amounts of SLC5A1, SLC2A2, SLC30A1, SLC11A2 and SLC7A1 in ileum of growing pigs. Results are presented as mean and SEM. a and b means without a common superscript differ $(P<0.05)$. Ab, pigs treated with antibiotics; Ab + SCFAs (AS), pigs treated with antibiotics and SCFAs (acetic, propionic and butyric acids; 61.84, 18.62, and 12.55 mM respectively).

present study. This is inconsistent with the previous research on mice, ${ }^{22}$ and the researchers found more than 400 folds decline of microbiota counts in antibiotic-treated mice when compared with untreated mice using this microbiota depletion protocol, suggesting that the microbiota depletion protocol used in mice may not fit for pigs, and the antibacterial effects of 
Table 7 Effect of SCFA on DNA and total protein concentrations of mucosa in ileum, cecum and colon of growing pigs ${ }^{a}$

\begin{tabular}{llllll}
\hline & & Ab + & & \\
Control & Ab & SCFAs (AS) & SEM & $P$ values \\
\hline
\end{tabular}

\section{DNA}

$\begin{array}{llllll}\text { Ileum }\left(\mu \mathrm{g} \mathrm{mg}^{-1}\right) & 1.033^{b} & 0.757^{c} & 1.175^{b} & 0.093 & 0.029 \\ \text { Cecum }\left(\mu \mathrm{g} \mathrm{mg}^{-1}\right) & 1.665 & 1.419 & 1.771 & 0.096 & 0.071 \\ \text { Colon }\left(\mu \mathrm{g} \mathrm{mg}^{-1}\right) & 1.550 & 1.309 & 1.701 & 0.091 & 0.037\end{array}$

\section{Protein}

Ileum $\left(\mathrm{mg}_{\text {prot }} \mathrm{g}^{-1}\right) \quad 41.931^{c} \quad 42.222^{c} \quad 51.918^{b}$

Cecum $\left(\begin{array}{llll}\left.\mathrm{mg}_{\text {prot }} \mathrm{g}^{-1}\right) & 25.102^{b, c} & 22.398^{c} & 29.589^{b}\end{array}\right.$

Colon $\left(\begin{array}{llll}\left.\mathrm{mg}_{\text {prot }} \mathrm{g}^{-1}\right) & 38.190^{c} & 38.387^{c} & 44.248^{b}\end{array}\right.$

$2.349 \quad 0.021$

$\begin{array}{ll}1.377 & 0.013\end{array}$

$0.966 \quad 0.002$
${ }^{a}$ Ab, pigs treated with antibiotics; Ab + SCFAs (AS), pigs treated with antibiotics and SCFAs (acetic, propionic and butyric acids; 61.84, 18.62, and $12.55 \mathrm{mM}$ respectively). ${ }^{b}$ Within a row, means a common superscript differ $(P<0.05) .{ }^{c}$ Without a row, means a common superscript differ $(P<0.05)$.

Table 8 Effect of SCFA on cytokines, GLP2 and SIgA concentration of ileum, cecum and colon in growing pigs ${ }^{a}$

\begin{tabular}{|c|c|c|c|c|c|}
\hline & Control & $\mathrm{Ab}$ & $\begin{array}{l}\mathrm{Ab}+ \\
\text { SCFAs (AS) }\end{array}$ & SEM & $P$ values \\
\hline \multicolumn{6}{|l|}{ Ileum } \\
\hline IL10 (ng g grot ${ }^{-1}$ ) & $3.859^{b}$ & 2.058 & $2.811^{c}$ & 0.143 & $<0.001$ \\
\hline IL8 (ng prot $^{-1}$ ) & $1.537^{b}$ & $1.129^{c}$ & $0.545^{c}$ & 0.080 & $<0.001$ \\
\hline $\mathrm{TNF} \alpha\left(\mathrm{ng} \mathrm{g}_{\text {prot }}{ }^{-1}\right)$ & $23.641^{b}$ & $12.058^{c}$ & $2.301^{c}$ & 1.482 & $<0.001$ \\
\hline GLP2 (pmol g prot $^{-1}$ ) & $2.890^{b}$ & $2.350^{c}$ & $2.825^{b}$ & 0.077 & 0.001 \\
\hline $\operatorname{SIgA}\left(\mu \mathrm{g} \mathrm{g}_{\text {prot }}{ }^{-1}\right)$ & 4.229 & 4.010 & 4.344 & 0.198 & 0.505 \\
\hline \multicolumn{6}{|l|}{ Cecum } \\
\hline IL10 (ng g prot $^{-1}$ ) & $4.357^{b}$ & $3.187^{c}$ & $3.902^{b, c}$ & 0.283 & 0.044 \\
\hline IL8 (ng g prot $^{-1}$ ) & $1.163^{b, c}$ & $1.339^{b}$ & $0.849^{c}$ & 0.105 & 0.023 \\
\hline $\mathrm{TNF} \alpha\left(\mathrm{ng} \mathrm{g}_{\text {prot }}{ }^{-1}\right)$ & $17.863^{b}$ & $19.794^{b}$ & $7.736^{c}$ & 1.368 & $<0.001$ \\
\hline GLP2 (pmol g prot $\left.^{-1}\right)$ & 5.658 & 5.011 & 5.764 & 0.206 & 0.055 \\
\hline $\operatorname{SIgA}\left(\mu \mathrm{g} \mathrm{g}_{\text {prot }}{ }^{-1}\right)$ & 8.001 & 7.461 & 7.762 & 0.465 & 0.721 \\
\hline \multicolumn{6}{|l|}{ Colon } \\
\hline IL10 (ng gprot $^{-1}$ ) & 2.753 & 2.465 & 2.946 & 0.206 & 0.295 \\
\hline IL8 (ng g grot $\left.{ }^{-1}\right)$ & $1.347^{b}$ & $1.236^{b, c}$ & $1.007^{c}$ & 0.087 & 0.053 \\
\hline $\mathrm{TNF} \alpha\left(\mathrm{ng}^{\mathrm{p} \mathrm{prot}^{-1}}\right)$ & $10.388^{b}$ & $3.696^{c}$ & $3.083^{c}$ & 0.708 & $<0.001$ \\
\hline GLP2 (pmol g prot $^{-1}$ ) & $3.271^{b}$ & $2.537^{c}$ & $3.126^{b}$ & 0.147 & 0.013 \\
\hline SIgA $\left(\mu \mathrm{g} \mathrm{g}_{\text {prot }}{ }^{-1}\right)$ & $4.378^{b}$ & $3.483^{c}$ & $4.183^{b}$ & 0.164 & 0.008 \\
\hline
\end{tabular}

${ }^{a} \mathrm{Ab}$, pigs treated with antibiotics; Ab + SCFAs (AS), pigs treated with antibiotics and SCFAs (acetic, propionic and butyric acids; 61.84, 18.62 , and $12.55 \mathrm{mM}$ respectively). ${ }^{b}$ Within a row, means a common superscript differ $(P<0.05) .{ }^{c}$ Without a row, means a common superscript differ $(P<0.05)$.

the antibiotics may depends on the manufacturers, sources and types.

In our previous study, we used beet pulp as a dietary fiber source to formulate a high fiber diet, through which to explore the effect of high/low fiber on gut health in growing pigs. In this research, we obtained two different SCFAs profiles of colon, the concentrations of acetic, propionic and butyric acids in highfiber group and low-fiber group are 61.84, 18.62, and 12.55 $\mathrm{mM}$ and 40.08, 15.41 and $9.78 \mathrm{mM}$, respectively. Besides, the promoted intestinal growth and enhanced gut barrier function were found in high fiber group compared with low fiber group (unpublished). Thus, we chose the SCFAs profile of high fiber group in the previous study to explore the effects of intraileal supply of SCFAs on gut health via fitting T-cannulas in the terminal ileum of pigs combined with microbiota depletion protocol. As is known to all, SCFAs are produced by the gut microbiota, and the numbers of microbiota are positive associated with SCFAs concentrations. ${ }^{31}$ In our present study, pigs treated with high dose of antibiotics without SCFAs infusion had lower contents of acetic acid, propionic acid and total SCFAs in the serum and ileum, and lower content of butyric acid in the ileum, which was generally in accordance with the decreased total viable bacteria and lower relative mRNA expressions of SCFAs receptors (FFAR3 and FFAR2) in the ileum and colon. In a study using sodium butyrate showed that pigs fed with sodium butyrate containing diet had higher serous butyric acid, ${ }^{32}$ and the similar results were found in lambs fed diet supplemented with $2.50 \%$ butyrate. ${ }^{33}$ In consistent, while pigs were infused with SCFAs in our study, higher concentrations of acetic acid, propionic acid, butyric acid and total SCFAs in the serum, ileum and colon, and higher concentrations of acetic acid, butyric acid and total SCFAs in cecum, along with higher relative mRNA expressions of FFAR3 in the colon, and FFAR2 in both ileum and colon were observed, which illustrated that our SCFAs infusion model was successful.

The effects of SCFAs on intestinal cell proliferation are controversial. Previous studies have shown that SCFAs or butyrate suppressed epithelial proliferation, decreased cell viability and induced apoptosis in vitro or cancerous rats. ${ }^{\mathbf{9}, 13,34}$ However, the studies in normal vivo or biopsies are adverse. A study on human colonic biopsies depicted SCFAs incubation for 3 hours resulted in an increase in the proportion of proliferating cells per crypt. ${ }^{35}$ Studies in rats also suggested that infusion of SCFAs could stimulate cell proliferation in the small intestine and colon when infused into the ileum or colon, and this effect was implemented via the autonomic nervous system, and was dose-dependent of SCFAs but independent of the presence of gut bacteria., ${ }^{\mathbf{9} 10}$ Peritoneal injection SCFAs stimulated the mitotic rate of the jejunal crypt cells, ${ }^{36}$ attenuated the level of CASP3, increased BCL2/BAX ratio possibly through inhibition of histone deacetylases, which resulted in the inhibition of apoptosis in a rat model. ${ }^{37}$ While lack of butyrate induced BAX gene expression paralleled by apoptosis of colonocytes in the proximal colon of guinea pig. ${ }^{38}$ Furthermore, the sole study using infusion model on pigs demonstrated cecal infusion of butyrate caused a $78-119 \%$ stimulation of epithelial cell proliferation in the jejunum, ileum, cecum and colon in suckling piglets. ${ }^{12}$ The stimulative proliferation effect was also observed in our study, the proportions of ileal and colonic apoptotic cells and $\mathrm{G}_{0} \mathrm{G}_{1}$ phase cells in SCFAs infusion group were lower, whereas the proportions of $S$ phase cells, $G_{2} M$ phase cells and proliferation index were higher than those in the $\mathrm{Ab}$ group, which were along with lower relative mRNA expressions of BAX, CASP3 and CDKN1A, and higher relative mRNA expressions of BCL2 and CCND1. SCFAs have apparently paradoxical effects on cellular proliferation and apoptosis, as they show stimulative proliferation effect in in vivo of normal gut or 

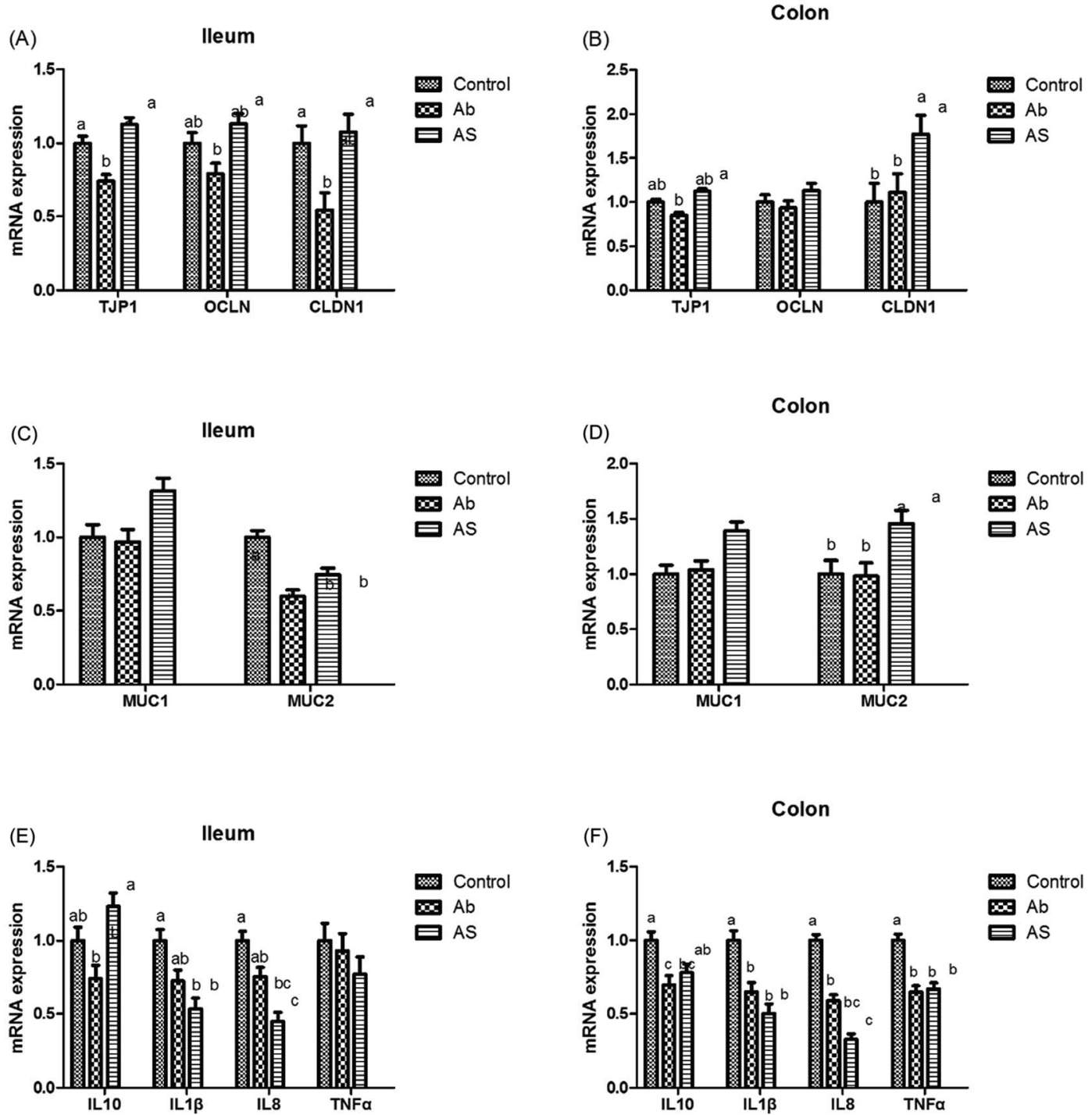

Fig. 5 The relative mRNA expressions of intestinal barrier-related genes. (A and B) Relative amounts of OCLN, TJP1 and CLDN1 mRNAs in ileum and colon of growing pigs. ( $C$ and D) Relative amounts of MUC1 and MUC2 mRNAs in ileum and colon of growing pigs. (E and F) Relative amounts of IL10, IL1 $\beta$, IL8 and TNF $\alpha$ mRNAs in ileum and colon of growing pigs. Results are presented as mean and SEM. a and $b$ means without a common superscript differ $(P<0.05)$. Ab, pigs treated with antibiotics; Ab + SCFAs (AS), pigs treated with antibiotics and SCFAs (acetic, propionic and butyric acids; $61.84,18.62$, and $12.55 \mathrm{mM}$ respectively).

the situations where the energy status of the intestinal epithelial cells is impaired, as well as germ free condition, fiber free diet and parenteral nutrition, and SCFAs display inhibitive proliferation effect in tumor cells, which depends on factors such as the intracellular milieu, availability of other metabolic substrate and the level of exposure. ${ }^{39,40}$ Due to the Warburg effect, glucose is the primary energy source using by cancerous colonocytes, so butyrate accumulated and functioned as an HDAC inhibitor, and thereby inhibits proliferation. However, when the Warburg effect was prevented from occurring, butyrate stimulated the proliferation of cancerous colonocytes, which could interpret the paradoxical effects of SCFAs, especially butyrate. ${ }^{41}$ Thus, we are confident that, in growing pigs, intraileal SCFAs infusion could stimulate cell proliferation.
In addition to promote cell proliferation, intracolonic infusion of butyrate or a combination of SCFAs for 7 days increased the concentrations of mucosal protein, RNA and DNA, as well as mucosal weight in colon, and increased the DNA concentrations of jejunum and ileum in rats. ${ }^{11}$ Intravenously administrated of SCFAs or butyrate to neonatal piglets with $80 \%$ jejunoileal resection increased villus height and proliferate cell nuclear antigen expression in the whole intestine.$^{42}$ Besides, dietary sodium butyrate supplementation markedly increased villous height and villus height: crypt depth in the intestine of pigs. ${ }^{32,43}$ These researches are generally consistent with our study, which demonstrated SCFAs infusion enhanced the relative length and relative weight of intestine, increased the villus height and villus height: crypt depth of duodenum and jejunum, and 
Table 9 Effect of SCFA on the ileal, caecal and colonic E. coli, Lactobacilli, Bifidobacterium spp. Bacteroides and Bacillus spp. of growing pigs (log copies per g) ${ }^{a}$

\begin{tabular}{lrrrrr}
\hline & & \multicolumn{3}{c}{ Ab +} \\
Items & Control & Ab & SCFAs (AS) & SEM & $P$ values \\
\hline Ileum & & & & & \\
Total bacteria & $10.369^{b}$ & $9.561^{c}$ & $9.733^{c}$ & 0.089 & $<0.001$ \\
Bacillus spp. & $9.935^{b}$ & $8.183^{c}$ & $9.968^{b}$ & 0.114 & $<0.001$ \\
Lactobacillus spp. & $8.096^{b}$ & $6.328^{c}$ & $8.092^{b}$ & 0.155 & $<0.001$ \\
Escherichia coli & $9.122^{b}$ & $8.076^{c}$ & 7.623 & 0.107 & $<0.001$ \\
Bifidobacterium spp. & $9.432^{b}$ & $8.337^{c}$ & $9.572^{b}$ & 0.184 & 0.001 \\
& & & & & \\
Cecum & & & & & \\
Total bacteria & $11.676^{b}$ & $11.246^{c}$ & $11.364^{c}$ & 0.038 & $<0.001$ \\
Bacillus spp. & $9.752^{b}$ & $9.533^{c}$ & $9.708^{a}$ & 0.023 & $<0.001$ \\
Lactobacillus spp. & $9.096^{b}$ & $8.423^{c}$ & $9.084^{a}$ & 0.084 & $<0.001$ \\
Escherichia coli & $9.910^{b}$ & $8.642^{c}$ & 7.927 & 0.104 & $<0.001$ \\
Bifidobacterium spp. & $9.782^{b}$ & $9.314^{c}$ & $9.718^{a}$ & 0.068 & 0.001 \\
& & & & & \\
Colon & & & & & \\
Total bacteria & $11.878^{b}$ & $11.342^{c}$ & $11.367^{c}$ & 0.043 & $<0.001$ \\
Bacillus spp. & $10.177^{b}$ & $9.704^{c}$ & $10.151^{b}$ & 0.039 & $<0.001$ \\
Lactobacillus spp. & $9.246^{b}$ & $8.504^{c}$ & $9.054^{b, c}$ & 0.149 & 0.014 \\
Escherichia coli & $9.155^{b}$ & $8.552^{c}$ & $8.420^{c}$ & 0.105 & 0.001 \\
Bifidobacterium spp. & $9.641^{b}$ & $8.746^{c}$ & $9.876^{b}$ & 0.154 & 0.001 \\
a & & & & &
\end{tabular}

${ }^{a}$ Ab, pigs treated with antibiotics; Ab + SCFAs (AS), pigs treated with antibiotics and SCFAs (acetic, propionic and butyric acids; 61.84, 18.62 , and $12.55 \mathrm{mM}$ respectively). ${ }^{b}$ Within a row, means a common superscript differ $(P<0.05) .{ }^{c}$ Without a row, means a common superscript differ $(P<0.05)$.

promoted DNA and protein concentrations in ileum and colon. It is well-known that IGF1, IGF1R, EGF, GLP2, and GLP2R are main regulators of intestine growth, ${ }^{\mathbf{4 4 , 4 5}}$ and higher relative mRNA expressions of these genes were found in present study with SCFAs infusion. Nevertheless, in an inconsistent study showed that cecal infusion butyrate did not affect villus height in pigs, and the author pointed out the means in each of the groups for each tissue was small but variable, which covered up the differences. ${ }^{12}$

Moreover, we cannot, however, ignore the mediation by gut hormones or humoral factors. ${ }^{46}$ In this study, SCFAs infusion groups had higher GLP2 concentration in the ileum and cecum than that in the Ab group. Consistent with this result, intravenous SCFAs supplementation increased ileal RNA, DNA and total protein concentrations, increased proliferation, as well as elevated ileal proglucagon expressions and plasma GLP2 concentration in total parenteral nutrition-rats or neonatal piglets with $80 \%$ jejunoileal resection. ${ }^{42,47}$ It is known to all, enteroglucagon is one of the most prominent hormones influenced mucosal growth, and intestinal proglucagon mRNA level and proglucagon-derived peptides concentrations are correlated with cellular proliferation during intestinal adaptation, ${ }^{\mathbf{4 8}}$ indicating SCFAs may be physiologic stimulators and influence intestinal proliferation and growth by stimulating proglucagonderived peptides secretion..$^{49}$ In addition, mice lacking FFAR3 or FFAR2 exhibited reduced SCFA-triggered glucagon-like peptide1 (GLP-1) and PYY secretion in vitro and in vivo, suggesting SCFAs stimulate hormone secretion via the SCFAs receptors. ${ }^{\mathbf{5 0 , 5 1}}$
In our study, the ATTD of EE, DM, CP, gross energy and crude ash, and the relative mRNA expression of SLC5A1, SLC2A2, SLC7A1, SLC30A1 and SLC11A2 in SCFAs infusion group were greater than those in the $\mathrm{Ab}$ group. In a study measured by Ussing-type chambers revealed that mucosal medium supplemented with SCFAs increased net calcium absorption in isolated epithelium in rats. ${ }^{52}$ Intravenous SCFAs supplementation elevated ileal GLUT2 mRNA expressions in total parenteral nutrition-rats. ${ }^{47}$ In a denervated autoperfused dog colon preparation, colonic instillation with acetate or a combination of SCFAs increased colonic blood flow and oxygen uptake. ${ }^{53}$ Besides, SCFAs also stimulated the colonic motility in rats. ${ }^{54}$ Taken together, there is an evidence that SCFAs may have a nutritional effect on the intestinal epithelium, further promote intestinal growth, and thus improve the digestive and absorptive functions.

As the metabolites of intestinal microbial fermentation of undigested carbohydrates in the hindgut, SCFAs is not only crucial for energy salvage and absorption of salt and water in the colon, but may also be the essential factor for the mediating intestinal barrier function. ${ }^{7,55}$ In physiological concentrations, SCFAs have been shown to increase transepithelial electrical resistance, promote intestinal epithelial restitution and cause a concentration-dependent decrease in paracellular permeability in vitro. ${ }^{56,57}$ Similar results were found by using colonic tissues from newborn rats. ${ }^{58}$ These results further prove that SCFAs promote epithelial barrier function at both tissue and animal level. It is well recognized that tight junction, adherens junction and desmosome are main components of the intestinal physical barrier between epithelial cells. ${ }^{59}$ Claudins and OCLN are the major transmembrane proteins that conducted to the paracellular seal, while TJP1 is a cytoplasmic plaque protein which interacts with cytoskeletal proteins and transmembrane proteins. ${ }^{60}$ The assembly of the tight junction proteins plays key role in the formation and maintenance of gut barrier. ${ }^{61}$ Our study revealed SCFAs infusion enhanced the relative mRNA expressions of TJP1, OCLN and CLDN1 in the ileum and colon compared with the Ab group. Likewise, the promoted intestinal physical barrier function of butyrate was likely to be explained by the increased levels of expression of OCLN and TJP1 in IPEC$\mathrm{J} 2$ cells and the up-regulation of CLDN1 transcription in cdx2IEC cells. ${ }^{\mathbf{1 4 , 6 2}}$ In the Caco-2 cell monolayer model, SCFAs or butyrate enhanced the intestinal physical barrier function by depleting intracellular $\mathrm{O}_{2}$, stabilizing the transcription factor HIF-1, leading to facilitate the assembly of tight junctions, and this dynamic process is regulated by the activation of AMPK or HIF-1, ${ }^{15,63}$ suggesting SCFAs could maintain the integrity of intestinal barrier via AMPK and HIF-1.

SCFAs have also been implicated in regulating the immune response. ${ }^{64}$ Previous study has shown that SCFAs could downregulate the pro-inflammatory cytokines gene expressions in intestinal epithelial cells induced by LPS, and thus benefited for epithelial immune barrier function. ${ }^{\mathbf{1 6}}$ It has been proposed that certain effects of SCFAs on gut function may occur through two SCFAs receptors. ${ }^{65}$ In studies on colitis revealed that exacerbated inflammation reaction was found in FFAR2-deficient mice, ${ }^{66}$ and SCFAs modulated the size and function of the 
colonic Treg pool in a FFAR2-dependent manner, ${ }^{67}$ suggesting stimulation of FFAR2 by SCFAs is essential for the normal resolution of certain inflammatory responses. Likely, disordered immune response was observed in FFAR3 and FFAR2deficient mice, and SCFAs motivated FFAR3 and FFAR2 on intestinal epithelial cells following administration of ethanol, and thus improved inflammatory responses through regulating ERK1/2 and MAPK signaling in mice. ${ }^{68}$ In a pig model revealed that dietary sodium butyrate supplementation reduced the TNFa and IL-6 levels in the serum. ${ }^{43}$ In accordance with previous studies, SCFAs infusion enhanced the relative mRNA expressions of IL10 and decreased the relative mRNA expressions of IL8, IL1 $\beta$ and TNF $\alpha$ in ileum and colon compared with the Ab group, accompanying with higher content of IL10 in the ileum and lower contents of IL8 and TNF $\alpha$ in the ileum and cecum, which indicated SCFAs were involved in improving intestinal immune barrier through SCFAs receptors.

Furthermore, SCFAs decreased $\mathrm{pH}$ values of digesta and inhibited harmful bacteria, further sustained gut microecosystem. ${ }^{4}$ In a study in vitro found that the Staphylococcus aureus internalization into bovine mammary epithelial cells was inhibited with the presence of propionic acid. ${ }^{17}$ Meanwhile, propionate has been shown to kill Salmonella or Escherichia coli at high acidity $(\mathrm{pH}=5){ }^{69}$ Increase the concentration of butyrate from 0 to $9 \mathrm{mM}$ resulted in elevated adherence of probiotics (Lactobacillus acidophilus ATCC 4356, Bifidobacterium longum ATCC 15707), which simultaneously reduced the adherent ability of Escherichia coli. ${ }^{18}$ Several animal studies also support such findings, dietary sodium butyrate supplementation markedly reduced the Clostridium and Escherichia coli, ${ }^{\mathbf{4}}$ and increased the number of Lactobacillus ssp. in the duodenum and ileum of pigs, ${ }^{32}$ and greater SCFAs production have been reported to decrease the numbers of potential pathogens (such as Escherichia coli and Salmonella) in pigs. ${ }^{70}$ Similar results were observed in our pig model, SCFAs infusion increased the numbers of Bacillus spp., Lactobacillus spp. and Bifidobacterium spp., and decreased the counts of Escherichia coli in ileum and cecum, suggesting SCFAs could decreased $\mathrm{pH}$ values, maintain the balance of gut microbiota, and thus improve intestinal biological barrier.

Finally, mucins secreted by goblet cells seem to contribute to a mucus layer between the luminal digesta and the mucosa, which provides a chemical barrier to intestine, and MUC2 is usually the most prominent mucin among the numerous mucins. ${ }^{71}$ An evidence showed that there was a positive correlation between the total thickness of the mucous layer and colonic SCFAs concentrations. ${ }^{72}$ In our study, SCFAs infusion enhanced the relative mRNA expressions of MUC2, accompanied with higher number of goblet cells, which is generally consistent with previous researches. Studies using cell culture models demonstrate that SCFAs stimulate MUC2 expression, leading to a better intestinal epithelial chemical barrier. ${ }^{73,74}$ Similarly, butyrate modulates mucin secretion in a dosedependent increase through MAPK signaling pathway, with peak effects at 6 or $9 \mathrm{mM}$, which was accompanied by the enhancement of the transcriptional levels of MUC2, MUC3, MUC4 and MUC12 in LS174T human colorectal cells. ${ }^{18}$ These studies correlate with our present study with respect to the effects of SCFAs on MUC2 expression revealed that SCFAs have the positive effect on intestinal chemical barrier.

Taken together, our study provides a framework on distal ileal infusion of SCFAs in a pig model, which found that SCFAs infusion increased proliferation of epithelial cells, stimulated intestinal DNA and protein concentrations, improved gut morphology and maintained the intestinal barrier through different mechanisms. However, some reports stated that excessive SCFAs could damage the intestinal function,,$^{7,75}$ so further research is needed to elucidate the effects of different SCFAs concentration with the same ratio on the development of gut.

\section{Conclusion}

In summary, treating pigs with high dose antibiotics could approximately decrease total fecal viable bacteria by 10 folds. Distal ileal infusion of SCFAs could increase SCFAs concentrations in serum and intestine, decrease apoptosis of epithelial cells, stimulate intestinal DNA and protein concentrations, improve gut morphology and maintain the intestinal physical barrier, chemical barrier, biological barrier and immune barrier function. Hence, this study provides the very first systematic evidence in a pig model that distal ileal infusion of SCFAs could stimulate intestinal growth and improve gut barrier function, and thus maintain gut health.

\section{Funding}

This study was financially supported by the National Natural Science Foundation of China (31672436), the earmarked fund for the China Agriculture Research System (CARS-36), Sichuan Province Science and Technology Support Project (2012NZ0001), the National Basic Research Program of China (2013CB531406), and the National High Technology Research and Development Program of China (2014AA022209).

\section{Authors' contributions}

DWC and XBM conceived the study and designed the experiment. HD and ARJ performed the experiments, including chemical analysis, analyzed the experimental data, and wrote the manuscript. JY and BY verified the validity of the experimentation and checked the results. JH, PZ, ZQH and YHL participated in its design and gave important intellectual advice for approval. All of the authors read and approved the final version of this manuscript.

\section{Competing interests}

The authors declare that they have no competing interests.

\section{Consent for publication}

Not applicable. 


\section{Ethics approval and consent to participate}

All experimental procedures and animal care were accomplished in accordance with the Guide for the Care and Use of Laboratory Animals provided by the Institutional Animal Care Advisory Committee for Sichuan Agricultural University. All animal protocols used in this study were approved by the Animal Care and Use Committee of Sichuan Agricultural University under permit number DKY-B20131703.

\section{Acknowledgements}

The authors wish to thank XP Shi from College of Veterinary Medicine, Sichuan Agricultural University, for the elaborative animal examination and surgery. We thank Kevin Morgen who is a native English speaker for the modification of the manuscript.

\section{References}

1 K. E. B. Knudsen, M. S. Hedemann and H. N. Lærke, Anim. Feed Sci. Technol., 2012, 173, 41-53.

2 P. Louis, K. P. Scott, S. H. Duncan and H. J. Flint, J. Appl. Microbiol., 2007, 102, 1197-1208.

3 M. Bugaut, Comp. Biochem. Physiol., Part B: Biochem. Mol. Biol., 1987, 86, 439-472.

4 S. H. Duncan, P. Louis, J. M. Thomson and H. J. Flint, Environ. Microbiol., 2009, 11, 2112-2122.

5 P. Louis and H. J. Flint, FEMS Microbiol. Lett., 2009, 294, 1-8.

6 F. De Vadder, P. Kovatcheva-Datchary, D. Goncalves, J. Vinera, C. Zitoun, A. Duchampt, F. Backhed and G. Mithieux, Cell, 2014, 156, 84-96.

7 J. Lin, Curr. Nutr. Food Sci., 2013, 9, 93-98.

8 W. Scheppach, Gut, 1994, 35, S35-S38.

9 T. Sakata, Br. J. Nutr., 1987, 58, 95-103.

10 T. Sakata and W. von Engelhardt, Comp. Biochem. Physiol., Part A: Mol. Integr. Physiol., 1983, 74, 459-462.

11 S. A. Kripke, A. D. Fox, J. M. Berman, R. G. Settle and J. L. Rombeau, JPEN, J. Parenter. Enteral Nutr., 1989, 13, 109-116.

12 C. L. Kien, R. Blauwiekel, J. Y. Bunn, T. L. Jetton, W. L. Frankel and J. J. Holst, J. Nutr., 2007, 137, 916-922.

13 L. Peng, Z. He, W. Chen, I. R. Holzman and J. Lin, Pediatr. Res., 2007, 61, 37-41.

14 X. Ma, P. X. Fan, L. S. Li, S. Y. Qiao, G. L. Zhang and D. F. Li, J. Anim. Sci., 2012, 90(Suppl 4), 266-268.

15 C. J. Kelly, L. Zheng, E. L. Campbell, B. Saeedi, C. C. Scholz, A. J. Bayless, K. E. Wilson, L. E. Glover, D. J. Kominsky and A. Magnuson, Cell Host Microbe, 2015, 17, 662-671.

16 C. Iraporda, A. Errea, D. E. Romanin, D. Cayet, E. Pereyra, O. Pignataro, J. C. Sirard, G. L. Garrote, A. G. Abraham and M. Rumbo, Immunobiology, 2015, 220, 1161-1169.

17 N. Alva-Murillo, A. Ochoa-Zarzosa and J. E. Lopez-Meza, Vet. Microbiol., 2012, 155, 324-331.

18 T. H. Jung, J. H. Park, W. M. Jeon and K. S. Han, Nutr. Res. Pract., 2015, 9, 343-349.
19 S. N. Heinritz, R. Mosenthin and E. Weiss, Nutr. Res. Rev., 2013, 26, 191-209.

20 C. Nyachoti, C. de Lange and V. Gabert, J. Anim. Sci., 2002, 80, 440-448.

21 R. Dilger, J. Sands, D. Ragland and O. Adeola, J. Anim. Sci., 2004, 82, 715-724.

22 A. J. Bruce-Keller, J. M. Salbaum, M. Luo, E. Blanchard, C. M. Taylor, D. A. Welsh and H. R. Berthoud, Biol. Psychiatry, 2015, 77, 607-615.

23 D. H. Reikvam, A. Erofeev, A. Sandvik, V. Grcic, F. L. Jahnsen, P. Gaustad, K. D. McCoy, A. J. Macpherson, L. A. MezaZepeda and F. E. Johansen, PLoS One, 2011, 6, e17996.

24 SASInstitute, 2001.

25 H. Diao, P. Zheng, B. Yu, J. He, X. Mao, J. Yu and D. Chen, Livest. Sci., 2014, 167, 249-256.

26 K. S. Kunert, A. S. Tisdale and I. K. Gipson, Arch. Ophthalmol., 2002, 120, 330-337.

27 H. Qi, Z. Xiang, G. Han, B. Yu, Z. Huang and D. Chen, Afr. J. Biotechnol., 2011, 10, 3704-3708.

28 N. Fierer, J. A. Jackson, R. Vilgalys and R. B. Jackson, Appl. Environ. Microbiol., 2005, 71, 4117-4120.

29 G. Q. Han, Z. T. Xiang, B. Yu, D. W. Chen, H. W. Qi, X. B. Mao, H. Chen, Q. Mao and Z. Q. Huang, Mol. Biol. Rep., 2012, 39, 1869-1876.

30 H. Diao, Z. Gao, B. Yu, P. Zheng, J. He, J. Yu, Z. Huang, D. Chen and X. Mao, J. Anim. Sci. Biotechnol., 2016, 7, 32.

31 C. P. Moran and F. Shanahan, Best Pract. Res., Clin. Gastroenterol., 2014, 28, 585-597.

32 P. Galfi and J. Bokori, Acta Vet. Hung., 1990, 38, 3-17.

33 D. J. Wilson, T. Mutsvangwa and G. B. Penner, J. Anim. Sci., 2012, 90, 3153-3161.

34 J. M. Clarke, G. P. Young, D. L. Topping, A. R. Bird, L. Cobiac, B. L. Scherer, J. G. Winkler and T. J. Lockett, Carcinogenesis, 2012, 33, 197-202.

35 H. P. Bartram, W. Scheppach, H. Schmid, A. Hofmann, G. Dusel, F. Richter, A. Richter and H. Kasper, Cancer Res., 1993, 53, 3283-3288.

36 P. J. M. Tutton and D. H. Barkla, Clin. Exp. Pharmacol. Physiol., 1982, 9, 671-674.

37 H. L. Sun, K. S. Song and J. Lee, J. Korean Soc. Appl. Biol. Chem., 2010, 53, 570-577.

38 R. Hass, R. Busche, L. Luciano, E. Reale and W. V. Engelhardt, Gastroenterology, 1997, 112, 875-881.

39 S. Senqupta, J. G. Muir and P. R. Gibson, J. Gastroenterol. Hepatol., 2006, 21, 209-218.

40 J. R. Lupton, Eur. J. Cancer Prev., 1995, 4, 373-378.

41 D. R. Donohoe, L. B. Collins, A. Wali, R. Bigler, W. Sun and S. J. Bultman, Mol. Cell., 2012, 48, 612-626.

42 A. L. Bartholome, D. M. Albin, D. H. Baker, J. J. Holst and K. A. Tappenden, JPEN, J. Parenter. Enteral Nutr., 2004, 28, 210-222; discussion 222-213.

43 Z. S. Wen, J. J. Lu and X. T. Zou, J. Anim. Vet. Adv., 2012, 11, 814-821.

44 J. Lovshin, B. Yusta, I. Iliopoulos, A. Migirdicyan, L. Dableh, P. L. Brubaker and D. J. Drucker, Endocrinology, 2000, 141, 4194-4201. 
45 C. B. Steeb, J. F. Trahair, F. M. Tomas and L. C. Read, Am. J. Physiol., 1994, 266, G1090-G1098.

46 T. Sakata and T. Yajima, Q. J. Exp. Physiol., 1984, 69, 639-648.

47 K. A. Tappenden and M. I. McBurney, Dig. Dis. Sci., 1998, 43, 1526-1536.

48 S. R. Bloom and J. M. Polak, Scand. J. Gastroenterol., Suppl., 1982, 74, 93-103.

49 K. A. Tappenden, L. A. Drozdowski, A. B. Thomson and M. I. McBurney, Am. J. Clin. Nutr., 1998, 68, 118-125.

50 A. Psichas, M. L. Sleeth, K. G. Murphy, L. Brooks, G. A. Bewick, A. C. Hanyaloglu, M. A. Ghatei, S. R. Bloom and G. Frost, Int. J. Obes., 2015, 39, 424-429.

51 G. Tolhurst, H. Heffron, Y. S. Lam, H. E. Parker, A. M. Habib, E. Diakogiannaki, J. Cameron, J. Grosse, F. Reimann and F. M. Gribble, Diabetes, 2012, 61, 364-371.

52 H. Mineo, H. Hara and F. Tomita, Life Sci., 2001, 69, 517-526. 53 P. R. Kvietys and D. N. Granger, Gastroenterology, 1981, 80, 962-969.

54 T. Yajima, J. Physiol., 1985, 368, 667-678.

55 I. R. Sanderson, J. Nutr., 2004, 134, 2450S-2454S.

56 A. J. Wilson and P. R. Gibson, Gastroenterology, 1997, 113, 487-496.

57 J. M. Mariadason, D. H. Barkla and P. R. Gibson, Am. J. Physiol., 1997, 272, G705-G712.

58 T. Suzuki, S. Yoshida and H. Hara, Br. J. Nutr., 2008, 100, 297-305.

59 M. Heiskala, P. A. Peterson and Y. Yang, Traffic, 2001, 2, 9398.

60 D. Yu and J. R. Turner, Biochim. Biophys. Acta, Biomembr., 2008, 1778, 709-716.

61 J. M. Anderson, C. M. Van Itallie and A. S. Fanning, Curr. Opin. Cell Biol., 2004, 16, 140-145.

62 H. B. Wang, P. Y. Wang, X. Wang, Y. L. Wan and Y. C. Liu, Dig. Dis. Sci., 2012, 57, 3126-3135.
63 L. Peng, Z. R. Li, R. S. Green, I. R. Holzman and J. Lin, J. Nutr., 2009, 139, 1619-1625.

64 K. A. Kles and E. B. Chang, Gastroenterology, 2006, 130, S100S105.

65 E. Le Poul, C. Loison, S. Struyf, J. Y. Springael, V. Lannoy, M. E. Decobecq, S. Brezillon, V. Dupriez, G. Vassart, J. Van Damme, M. Parmentier and M. Detheux, J. Biol. Chem., 2003, 278, 25481-25489.

66 K. M. Maslowski, A. T. Vieira, A. Ng, J. Kranich, F. Sierro, D. Yu, H. C. Schilter, M. S. Rolph, F. Mackay, D. Artis, R. J. Xavier, M. M. Teixeira and C. R. Mackay, Nature, 2009, 461, 1282-1286.

67 P. M. Smith, M. R. Howitt, N. Panikov, M. Michaud, C. A. Gallini, Y. M. Bohlooly, J. N. Glickman and W. S. Garrett, Science, 2013, 341, 569-573.

68 M. H. Kim, S. G. Kang, J. H. Park, M. Yanagisawa and C. H. Kim, Gastroenterology, 2013, 145, 396-406.

69 C. A. Cherrington, M. Hinton, G. R. Pearson and I. Chopra, J. Appl. Bacteriol., 1991, 70, 161-165.

70 L. Prohászka, B. M. Jayarao, Á. Fábiá and S. Kovács, J. Vet. Med., Ser. B, 1990, 37, 570-574.

71 J. T. Lamont, Ann. N. Y. Acad. Sci., 1992, 664, 190-201.

72 M. S. Hedemann, P. K. Theil and K. E. Bach Knudsen, Br. J. Nutr., 2009, 102, 117-125.

73 L. E. Willemsen, M. A. Koetsier, S. J. van Deventer and E. A. van Tol, Gut, 2003, 52, 1442-1447.

74 N. Burger-van Paassen, A. Vincent, P. J. Puiman, M. van der Sluis, J. Bouma, G. Boehm, J. B. van Goudoever, I. van Seuningen and I. B. Renes, Biochem. J., 2009, 420, 211-219.

75 S. Ploger, F. Stumpff, G. B. Penner, J. D. Schulzke, G. Gabel, H. Martens, Z. Shen, D. Gunzel and J. R. Aschenbach, Ann. N. Y. Acad. Sci., 2012, 1258, 52-59. 